\title{
Entre escravos e livres: economia e força de trabalho no Vale do Paraíba e no Oeste Paulista no terceiro quartel do século XIX*
}

\section{Among slaves and free workers: economy and labor force in São Paulo in the second part of the $19^{\text {th }}$ century}

\section{Marcelo Freitas Soares de Moraes Cruz}

Universidade de São Paulo

\section{Resumo}

O artigo traz uma análise da estrutura da força de trabalho posicionada no Vale do Paraíba e no Oeste Paulista. A partir dos dados do censo de 1872, buscamos verificar empiricamente a proporção de trabalhadores livres e escravizados na força de trabalho, e sua segmentação entre as atividades econômicas. Constatou-se que a expansão da economia agrícola, puxada pela lavoura cafeeira, foi responsável pela mobilização de uma parcela da força de trabalho livre muito maior do que foi previsto nos estudos clássicos da história econômica.

Palavras-chave: Força de trabalho; Escravidão; Trabalho livre; Economia cafeeira.

\begin{abstract}
This paper presents an analysis of the structure of the labor force positioned in Vale do Paraíba and the west region of São Paulo state, in Brazil. Relying on data from the 1872 census, our main effort was to find, based on empirical methods, the ratio between free and slave labor force, and its distribution among economic activities. It has been found that the expansion of agricultural economy, driven by coffee production, was responsible for mobilization of free labor, in far higher levels than originally presumed in traditional studies on economic history.
\end{abstract}

Keywords: Labor force; Slavery; Free labor; Coffee economy.

\footnotetext{
* Uma versão preliminar deste trabalho foi apresentada no Simpósio "Metodologia e fontes para os estudos de família, gênero, qualidade e mestiçagem nas sociedades do passado. Etapa protoestatística e estatística”, no âmbito do $8^{\circ}$ Congresso Internacional CEISAL, realizado em Salamanca, Espanha, entre 28 de junho e $1^{\circ}$ de julho de 2016.
} 

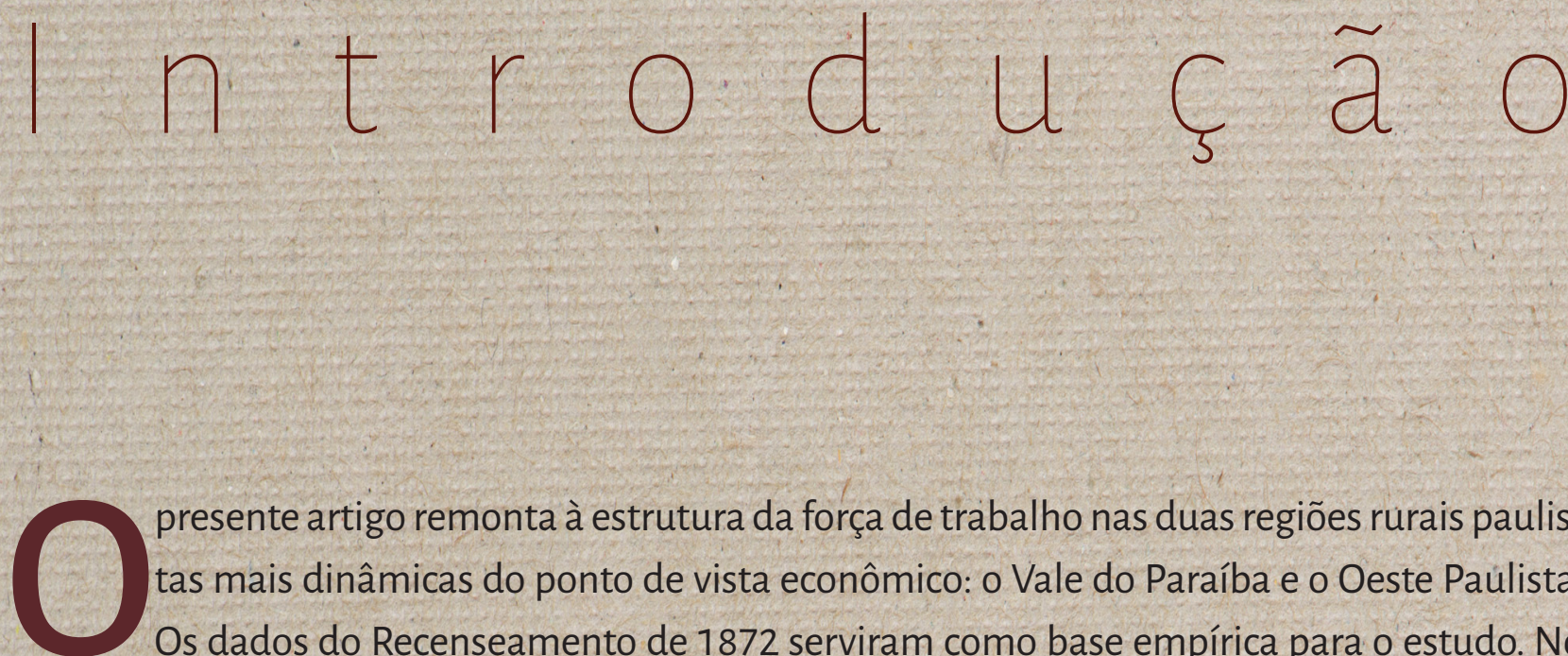

presente artigo remonta à estrutura da força de trabalho nas duas regiões rurais paulistas mais dinâmicas do ponto de vista econômico: o Vale do Paraíba e o Oeste Paúlista. Os dados do Recenseamento de 1872 serviram como base empírica para o estudo. No terceiro quartel do século XIX, a cultura cafeeirá do Vale deixava para trás seu apogeu produtivo, enquanto a região do Oeste Paulista experimentava uma voraz expansão da cafeicultura.

A pesquisa foi guiada por dois objetivos. O primeiro foi buscar contornos empíricos para a proporção entre trabalhadores escravos e livres na força de trabalho engatada na agricultura paulista. O segundo foi verificar a participação da população livre e escrava em atividades não agrícolas, como a manufatura/artesanato, em um contexto marcado pela expansão da fronteira agrícola, aumento da demanda por trabalho e encarecimento do braço cativo. Enfrentamos essas problemáticas de pesquisa utilizando as tabulações do recenseamento que dividem a população paulista ao largo das mais variadas profissões.

Circunscrevemos as regiões rurais destacadas para o estudo através de amostras formadas por cidades de cada uma delas. Do Vale, foram selecionadas as cidades de Bananal, Areias, Taubaté, Jacareí, São José do Barreiro, Pindamonhangaba e Paraibuna. A amostra do Oeste Paulista foi composta pelos municípios de Jundiaí, Casa Branca, Campinas, Piracicaba, Rio Claro, Sorocaba e Atibaia.

\section{Expansão da economia e a dificuldade na reprodução do capital escravista mercantil}

Havia dois complexos escravistas montados no Brasil durante a segunda metade do século XIX. Tratam-se do complexo nordestino e o do centro-sul (SLENES, 2004, p. 326). Ambos eram caracterizados pela produção de uma miríade de gêneros orientados para os mercados interno e externo. Entretanto, o foco na camada superior da economia rural jogava luz, no caso nordes- 
tino, sobre a produção de açúcar e de algodão. Aplicado ao do centro-sul, esse foco mostrava uma lavoura exportadora escravista dividida em torno da produção de açúcar, algodão e café.

O dinamismo econômico destes complexos escravistas era dado, na segunda metade do século XIX, através de suas interações estabelecidas com o centro do capitalismo mundial. Esse momento coincide com a disseminação de sistemas industriais modernos na Europa e nos Estados Unidos. $\mathrm{O}$ avanço da industrialização para segmentos tecnologicamente avançados conferiu protagonismo aos centros urbanos e promoveu a expansão dos grupos sociais de renda média, marcando a emergência de padrões de consumo em massa. Segundo Tomich (2010, p. 110), essas transformações foram responsáveis pelo aumento da demanda no mercado internacional de commodities. A reação apresentada pelos dois complexos escravistas do Império, diante dos estímulos externos, foi distinta.

De um lado, a produção nordestina de açúcar foi incapaz de competir com a mais eficiente e moderna produção cubana. De outro, o centro-sul do Império apresentou reação agressiva aos estímulos colocados no âmbito do mercado mundial. Neste caso, o dinamismo da demanda encontrou resposta adequada pelo lado da oferta, expressa na expansão da fronteira agrícola e no vigoroso crescimento das exportações da rubiácea.

Posicionemos as duas regiões rurais de São Paulo nessa trajetória de avanço da lavoura cafeeira. O Vale do Rio Paraíba do final dos setecentos era uma região pobre, caracterizada pela policultura sem orientação comercial. Nas primeiras décadas dos oitocentos, o café se alastrou rapidamente das proximidades da Capital Imperial em direção ao Vale do Paraíba. Em sua parcela paulista, a onda verde foi responsável pela formação de importantes municípios cafeeiros, como Areias e Bananal.

A gênese da lavoura escravista de exportação imprimiu dinamismo econômico e demográfico aos núcleos populacionais cafeeiros do Vale. Ele se manifestou atrạvés da pujante absorção de mão de obra escravizada; da disseminação da plantation; e da integração dessa lavoura no comércio internacional. A produção foi ascendente nessa região. Em meados da década de 1830, Areias e Bananal estavam no grupo das principais regiões exportadoras do Império (MOTTA, 2012, p. 40).

Cabe lembrar que a especialização na cultura cafeeira não era uma marca geral da camada superior do agro valeparaibano. Lorena, São José do Barreiro e Taubaté dividiam seus principais fatores de produção entre as lavouras cafeeira e canavieira.

O Oeste Paulista apresentou trajetória econômica diferente. O impulso para o desenvolvimento do capital escravista mercantil (PIRES \& COSTA, 2010, p. 13) ocorreu no final do século XVIII, 
através da lavoura canavieira. Petrone (1968) remontou o desenvolvimento do quadrilátero do açúcar, formado por Sorocaba, Piracicaba,'Mogi-Cuaçu e Jundiaí. Sua produção abastecia os mercados de Minas Cerais e do Rio de Janeiro com derivados da cana.

A partir da década de 1840 , a região passou por uma transição para o café. Utilizando dados da Barreira de Cubatão, rota para o porto de Santos, a autora percebeu que, já em 1850, o volume exportado de café havia ultrapassado o de açúcar e de aguardente. Esta mudança envolveu transferência dos principais ativos de uma cultura para a outra: os escravos e as terras mais férteis (PETRONE, 1968, p. 162). Sua motivação foi a dinâmica de preços do açúcar e do café no mercado internacional. Entretanto, foi uma transição parcial, uma vez que a maior parte dos municípios, como Piracicaba, continuavam produzindo derivados da cana.

Tabela 1 - Produção de Café na Província de São Paulo (em arrobas).

\begin{tabular}{|l|c|c|c|c|}
\hline Localidade & $\mathbf{1 8 5 4}$ & \% do total & $\mathbf{1 8 8 6}$ & \% do total \\
\hline Vale do Paraíba $^{*}$ & 2.737 .639 & 77,5 & 2.074 .267 & 20 \\
\hline Oeste Velho & 796.617 & 22,5 & 7.729 .083 & 74,5 \\
\hline Província de São Paulo & 3.534 .256 & 100 & 10.374 .350 & 100 \\
\hline
\end{tabular}

Fonte: Milliet (1982, p. 21-22). "Engloba a região do Litoral Norte. "*Engloba as regiões central, paulista e mogiana.

As evidências presentes na Tabela 1 indicam que ambas as regiões passavam por processos econômicos distintos durante a segunda metade do século XIX. De um lado, houve a perda de fôlego produtivo por parte da cafeicultura valeparaibana, devido ao esgotamento dos solos. De outro, ocorria rápida expansão desta lavoura no Oeste Paulista, onde fora notável o ímpeto exportador dos produtores de Campinas.

O censo estudado foi produzido em 1874 . Trata-se de um momento situado em meio a estes dois processos, mais especificamente quando o esgotamento dos solos apenas iniciava o processo de solapamento dos fundamentos econômicos da acumulação no Vale. Portanto, devemos salientar que essa região ainda mantinha sua primazia, na Província, nos quesitos produção e exportação da rubiácea durante a década de 1870 (HOLLOWAY, 1984, p. 22).

A Tabela 2 permite a visualização dos dados referentes à produção de café nas cidades selecionadas para o estudo. São eștimativas arroladas por Milliet (1982). É notória a importância dessa lavoura nas localidades que formam nossas amostras. 
Tabela 2-Produção de Café nas cidades que compõem as amostras (em arrobas).

\begin{tabular}{|l|c|c|c|}
\hline Localidade & 1836 & 1854 & 1886 \\
\hline Bananal & 64.822 & 554.600 & 100.000 \\
\hline Areias & 102.797 & 186.094 & 300.000 \\
\hline Taubaté & 23.607 & 354.730 & 56.000 \\
\hline Jacareí & 54.004 & 240.000 & 11.159 \\
\hline Paraibuna & 3.179 & 7.261 & 173.333 \\
\hline São José do Barreiro & - & - & 200.000 \\
\hline Pindamonhangaba & 62.628 & 350.000 & 840.492 \\
\hline Amostra-Vale do Paraíba & 311.037 & 1.692 .685 & 1.500 .000 \\
\hline Campinas & & 335.550 & 300.000 \\
\hline Piracicaba & 4.699 & - & 600.000 \\
\hline Rio Claro & - & 99.670 & 2.833 .333 \\
\hline Sorocaba & 770 & 12.750 & 300.000 \\
\hline Casa Branca & 5.958 & 1.750 & 133.333 \\
\hline Jundiaí & & 60.000 & - \\
\hline Atibaia & & 515.820 & \\
\hline Amostra-Oeste Paulista & & & \\
\hline
\end{tabular}

Fontes: dados para o ano de 1836: Müller (1978, p. 124-127); dados para os anos de 1854 e 1886: Milliet (1982, p. 41, p. 48, p. 53-54).

Apesar do peso relevante na estrutura produtiva, havia grande disparidade no que diz respeito à quantidade de café produzido nas localidades. Infelizmente, não dispomos de uma base de dados sobre produção de café com cobertura sobre todas eśsas cidades para a década de 1870 . Porém, podemos inferir que Bananal, Pindamonhangaba, Areias e Taubaté, pelo lado do Vale, ainda continuaram se destacando como grandes produtores na primeira metade da década de 1870. Já pelo lado do Oeste Paulista, Campinas, Piracicaba, Rio Claro, Casa Branca e Jundiaí foram importantes arenas da expansão cafeeira.

O Almanak da Provincia de São Paulo (1873 apud LUNÉ \& FONSECA, 1985) traz informações que nos ajudam a remontar o panorama produtivo das cidades que compõem as amostras regionais deste estudo. A fonte menciona as culturas de destaque de cada uma das cidades. Foi possível resgatar o papel preponderante do café, da cana e do algodão nas regiões. 
A produção deste último gênero também apresentou crescimento em São Paulo entre as décadas de 1860 e 1870. As causas desse florescimento residem na desarticulação da economia do sul dos Estados Unidos durante a Guerra de Secessão. A redução da oferta no mercado internacional estimulou a produção em regiões de menor produtividade relativa. Essas aproveitaram a conjuntura favorável ao vincular-se à demanda da manufatura têxtil europeia. Sorocaba era a principal zona produtora de algodão da Província.

Tabela 3 - Principais culturas nas cidades que compõem a amostra (1873)

\begin{tabular}{|c|c|}
\hline Localidade & Principais culturas \\
\hline Bananal & Café \\
\hline Areias & Café \\
\hline Taubaté & Café, Cana e Algodão \\
\hline Jacareí & Café \\
\hline Paraibuna & Café e Algodão \\
\hline São José do Barreiro & Café e Cana \\
\hline Pindamonhangaba & Café e Algodão \\
\hline Campinas & Café e Cana \\
\hline Piracicaba & Café, Cana e Algodão \\
\hline Rio Claro & Café e Cana \\
\hline Sorocaba & Algodão e Gêneros Alimentícios \\
\hline Casa Branca & Café, Cana, Algodão e Fumo \\
\hline Jundiaí & Café, Algodão e Cana \\
\hline Atibaia & Café, Algodão e Gêneros Alimentícios \\
\hline
\end{tabular}

Fonte: Luné e Fonseca (1985, p: 147-158).

O pujante crescimento apresentado pela economia rural paulista ao longo do terceiro quartel do século XIX foi marcado pelo aumento no nível de especialização produtiva nas culturas mais nobres e pelo protagonismo dos agricultores escravistas na expansão do produto. Cabe ressaltar, entretanto, a faceta relativa deste processo, uma vez que tal expansão não negava a 
presença de pequenos agricultores não escravistas, e nem a produção de alimentos na estrutura produtiva.

O panorama das realidades econômicas em tela só se torna completo com uma apreciação acerca da principal relação social de produção, responsável pela maior parte da riqueza produzida nas duas parcelas do agro paulista: a escravidão.

No terceiro quartel dos oitocentos, a elevação do preço dos cativos trouxe dificuldades para a reprodução do capital escravista mercantil. Essa elevação era causada pelo encerramento do tráfico atlântico e por um descompasso entre demanda e oferta de trabalho (EISENBERC, 1989, p. 230). Esse último problema era latente no Oeste Paulista, onde uma voraz expansão da fronteira agrícola estava em movimento. Tendo em vista a importância econômica do escravismo, é possível dizer que esse efeito de elevação dos custos afetava o mercado de trabalho e a lucratividade do setor.

A valorização do braço cativo no principal mercado brasileiro, o Rio de Janeiro, foi de $200 \%$ entre 1850 e 1874. Houve viés de alta dos preços durante essa última década. $\mathrm{O}$ ano de 1872 marcou o início de uma escalada nos preços, interrompida apenas em 1877. A valorização foi de $30 \%$ nesse curto período (COLDSMITH, 1986, p. 30-31). As estimativas de preços apresentadas por Dean (1977, p. 66) para Rio Claro indicam que o valor médio dos escravos do sexo masculino aumentou 54\% entre as décadas de 1850 e 1870.

Cabe salientar também que o tráfico interno atingiu o auge de sua intensidade nessa última década (MOTTA, 2012, p. 163). Ele foi importante no Vale e, sobretudo, no Oeste. A dinâmica do preço dos cativos representou um problema real para os fazendeiros que precisavam ampliar seus planteis. Porém, a intensidade desse problema apresentou manifestações distintas nas duas zonas agrícolas.

Por um lado, os fazendeiros valeparaibanos foram menos afetadas por essa problemática relacionada à oferta do braço cativo. Em torno dos núcleos urbanos da região estavam assentadas sociedades escravistas maduras, formadas através de intensa relação com o tráfico atlântico até 1850. Portanto, a reposição de trabalhadores escravos só era necessária quando as famílias escravas constituídas nas fazendas não eram capazes de exercer esta função.

Por outro lado, a gestação da lavoura cafeeira escravista no núcleo do antigo quadrilátero do açúcar apresentou maior dependência em relação ao tráfico interno e ao recurso ao trabalho 
livre, sobretudo na montagem das fazendas durante a segunda metade dos oitocentos. Essa é a região que apresentava maior demanda por mão de obra.

Tal conjuntura complicada enfrentada pelos agentes econômicos não impediu a reprodução da' plantation no Vale do Paraíba e nem sua expansão no Oeste Paulista. Apesar da alta nos custos da aquisição de escravos, a população cativa cresceu $33 \%$ em São Paulo entre a promulgação da Lei Eusébio de Queiroz e a realização da pesquisa censitária na Província. Devemos encarar o aumento absoluto do número de cativos à luz de duas modificações demográficas em curso no terceiro quartel dos oitocentos.

Em primeiro lugar, seu crescimento não impediu a redução do peso relativo dos escravos na totalidade da população. O número de cativos saltou de 117.238 , em 1854 , para 156.612 , em 1874. Entretanto, o peso relativo destes na população total declinou de $28,5 \%$ para $18,7 \%$ (ElSENBERG, 1989, p. 225). Em segundo lugar, ocorreu um processo de concentração de escravos nas parcelas mais dinâmicas do agro, identificadas com o café (MATTOS, 2015, p. 146). Tal processo corroborou o papel essencial da escravidão na organização do sistema de grande lavoura entre as décadas de 60 e 70 do século XIX (LUNA \& KLEIN, 2010, p. 91).

Tabela 4 - Condição Social da População - Vale do Paraíba e Oeste Paulista (1874)

\begin{tabular}{|l|c|c|}
\hline Localidade & Livres & Escravos \\
\hline Vale do Paraíba & $80,7 \%$ & $23 \%, 3 \%$ \\
\hline Oeste Paulista & $77 \%$ & $28,2 \%$ \\
\hline Amostra Vale do Paraíba & $71,8 \%$ & $30,5 \%$ \\
\hline Amostra Oeste Paulista & $69,5 \%$ & $18 \%$ \\
\hline Província de São Paulo & $82 \%$ & \\
\hline
\end{tabular}

"Fonte: Eisenberg (1989, p. 226). Obs: Os dados para o Vale do Paraíba e do Oeste Velho incluem, respectivamente, o Litoral Norte e a Zona Central.

A Tabela 4 é estratégica em nossa análise por três motivos. Em primeiro lugar, ela informa que a presença cativa continuava sendo muito elevada nos dois espaços econômicos estudados. Ou seja, traz a evidência empírica do processo de concentração de escravos ao qual fizemos menção. Trata-se, também, de um indicativo importante acerca do desenvolvimento da agricultura 
comercial sob a égide da escravidão em São Paulo. O padrão de lucratividade alcançado por esse tipo de lavoura permitiu que as dificuldades na reprodução do escravismo fossem contornadas.

Em segundo lugar, podemos afirmar que o peso relativo dos escravos no total da população do Oeste Paulista era ligeiramente superior ao do Vale. Significa dizer que a primeira região operava com taxas de investimento mais elevadas que a segunda - fato explicado pelo Oeste ter composto a fronteira agrícola da Província. Segundo Motta (2012, p. 153), a população cativa de Piracicaba quadruplicou entre 1850 e 1870.

Por fim, as amostras retiradas do censo para as duas regiões apresentam maior peso demográfico relativo para a população escrava do que a realidade captada nos dados compilados na obra de Eisenberg (1989, p. 229), que é mais ampla do ponto de vista geográfico. Significa dizer que nossas amostras captam franjas das duas regiões dotadas de maior capacidade em concentrar escravos.

\section{Análise da estrutura da força de trabalho}

Nesta seção, a estrutura da força de trabalho das duas regiões será analisada. Os dados censitários formam a base empírica da análise. Utilizamos os dados do censo de 1872 tabulados pelo Núcleo de Estudos de População “Elza Brequó" (Nepo/Unicamp). Os dados da província de São Paulo estão organizados na publicação São Paulo do Passado: Dados do Passa'do, organizada por Maria Silvia Bassanezi e sua equipe (BASSANEZI, 1998).

Primeiramente, serão apresentados os dados demográficos básicos, que fornecem uma visão geral sobre a divisão da população entre livres e escravos e sobre as dimensões da população em idade ativa (PIA) em cada uma das localidades.

Apesar de cobrir regiões nas quais o braço escravo se concentrava, notamos que o peso relativo desse grupo no total da população variava bastante entre os municípios. Bananal e São José do Barreiro, no Vale, e Campinas, no Oeste, destacavam-se enquanto zonas de altíssima concentração de cativos. Como mencionamos, eram localidades líderes do setor exportador. Nas cidades do Vale, com exceção dos habitantes de Bananal e de São José do Barreiro, a população livre for- 
mava, em média, $80 \%$ da população. No Oeste, com exceção da população de Campinas, os livres atingiam $76 \%$ do total. Portanto, era nítido o predomínio dos livres na estrutura demográfica.

Tabela 5 - Populaçãoe Condição Social (1874).

\begin{tabular}{|c|c|c|c|}
\hline Localidade & Livres & Escravos & Total \\
\hline Bananal & $7.325(47 \%)$ & $8.281(53 \%)$ & $15.606(100 \%)$ \\
\hline Areias & $3.819(66,8 \%)$ & $1.898(33,2 \%)$ & $5.717(100 \%)$ \\
\hline Taubaté & $15.225(80,4 \%)$ & $3.708(19,6 \%)$ & $18.933(100 \%)$ \\
\hline Jacareí & $8.629(84,5 \%)$ & $1.574(15,5 \%)$ & $10.203(100 \%)$ \\
\hline Paraibuna & $9.048(89,3 \%)$ & $1.084(10,7 \%)$ & $10.132(100 \%)$ \\
\hline São José do Barreiro & $3.125(55 \%)$ & $2.544(45 \%)$ & $5.669(100 \%)$ \\
\hline Pindamonhangaba & $10.918(74,6 \%)$ & $3.718(25,4 \%)$ & $14.636(100 \%)$ \\
\hline Campinas & $17.712(56,4 \%)$ & $13.685(43,6 \%)$ & 31.397 (100\%) \\
\hline Piracicaba & $13.566(71,5 \%)$ & $5.414(28,5 \%)$ & $18.980(100 \%)$ \\
\hline Rio Claro & 11.100 (73,8\%) & $3.935(26,2 \%)$ & $15.035(100 \%)$ \\
\hline Sorocaba & $10.543(75,3 \%)$ & $3.456(24,7 \%)$ & $13.999(100 \%)$ \\
\hline Casa Branca & $8.649(78 \%)$ & $2.414(22 \%)$ & $11.063(100 \%)$ \\
\hline Jundiaí & $5.953(76 \%)$ & $1.852(24 \%)$ & $7.805(100 \%)$ \\
\hline Atibaia & $5.080(82,7 \%)$ & $1.066(17,3 \%)$ & $6.146(100 \%)$ \\
\hline Vale do Paraíba & $58.089(71,8 \%)$ & $22.807(28,2 \%)$ & $80.896(100 \%)$ \\
\hline Oeste Paulista & $72.603(69,5 \%)$ & $31.822(30,5 \%)$ & $104.425(100 \%)$ \\
\hline São Paulo-Província & $680.742(81,3 \%)$ & $156.612(18,7 \%)$ & $837.354(100 \%)$ \\
\hline
\end{tabular}

Fonte: Elaboração própria a partir das tabulações organizadas em Bassanezi (1998, p. 37).

A análise da força de trabalho requer a delimitação da população em idade ativa. Essa categoria permite avaliar a participação relativa das pessoas arroladas no censo em cada uma das profissões diante da parcela da população com potencial participação na força de trabalho. Dessa forma, é possível verificar, por exemplo, a participação dos escravos vinculados à faina agrícola diante dos potenciais trabalhadores da sociedade em tela.

Diante de uma sociedade rural e escravista, consideramos que apenas as crianças menores de 11 anos estariam necessariamente excluídas da força de trabalho. Idosos não têm o mesmo vigor físico dos jovens, mas é possível que boa parte deles continuassem exercendo tarefas em 
fazendas, sítios ou nos acanhados ambientes urbanos constituídos em meio à lavoura exportadora. Por isto, utilizamos um conceito amplo de PIA, que não exclui os idosos.

É preciso adaptar o conceito de PIA à realidade escravista. A cisão da população e, consequen-' temente, da força de trabalho entre livres e escravos requer a divisão da PIA de acordo com a condição social. De um lado, temos a população livre em idade ativa (PLIA). De outro, a população escrava em idade ativa (PEIA). Os dados seguem abaixo:

Tabela 6 - População em Idade Ativa - Livres e Escravos.

\begin{tabular}{|c|c|c|c|c|c|c|}
\hline Localidade & Livres (PLIA) & PLIA/ PLT & Escravos (PEIA) & PEIA/PET & PIA Total & PIA/PT \\
\hline Bananal & $5.055(41 \%)$ & $69 \%$ & $7.272(59 \%)$ & $89 \%$ & $12.327(100 \%)$ & $79 \%$ \\
\hline Areias & 2.949 (64\%) & $77,2 \%$ & $1.651(36 \%)$ & $86,9 \%$ & $4.600(100 \%)$ & $80,4 \%$ \\
\hline Taubaté & $11.519(79,6 \%)$ & $75,6 \%$ & $2.954(20,4 \%)$ & $79,6 \%$ & $14.473(100 \%)$ & $76,4 \%$ \\
\hline Jacareí & $6.413(82,8 \%)$ & $74,3 \%$ & $1.334(17,2 \%)$ & $84,7 \%$ & 7.747 (100\%) & $75,9 \%$ \\
\hline Paraibuna & $6.137(88,6 \%)$ & $67,8 \%$ & $783(11, \%)$ & $72,2 \%$ & $6.920(100 \%)$ & $68,2 \%$ \\
\hline São José do Barreiro & $2.435(52,9 \%)$ & $77,9 \%$ & $2.174(47,1 \%)$ & $85,4 \%$ & $4.609(100 \%)$ & $81,3 \%$ \\
\hline Pindamonhangaba & $8.004(73,2 \%)$ & $73,3 \%$ & $2.936(26,8 \%)$ & $78,9 \%$ & $10.940(100 \%)$ & $74,7 \%$ \\
\hline Campinas & $11.838(51,4 \%)$ & $66,8 \%$ & $11.193(48,6 \%)$ & $81,7 \%$ & $23.031(100 \%)$ & $73,3 \%$ \\
\hline Piracicaba & 9.789 (69\%) & $72,1 \%$ & $4.383(31 \%)$ & $80,9 \%$ & $14.172(100 \%)$ & $74,6 \%$ \\
\hline Rio Claro & 7.331 (67,9\%) & $66 \%$ & $3.470(32,1 \%)$ & $88,1 \%$ & $10.801(100 \%)$ & $71,8 \%$ \\
\hline Sorocaba & 7.289 (70,6\%) & $69,1 \%$ & $3.043(29,4 \%)$ & $88 \%$ & $10.332(100 \%)$ & $73,8 \%$ \\
\hline Casa Branca & $6.261(75,6 \%)$ & $72,3 \%$ & $2.027(24,4 \%$ & $83,9 \%$ & $8.288(100 \%)$ & $74,9 \%$ \\
\hline Jundiaí & $4.210(72,3 \%)$ & $70,7 \%$ & $1.615(27,7 \%)$ & $87,2 \%$ & $5.825(100 \%)$ & $74,6 \%$ \\
\hline Atibaia & 3.897 (81\%) & $76,7 \%$ & 919 (19\%) & $86,2 \%$ & $4.816(100 \%)$ & $78,3 \%$ \\
\hline Vale do Paraíba & $6.073(69 \%)$ & $73,1 \%$ & $2.729(31 \%)$ & $83,7 \%$ & $8.802(100 \%)$ & $76,1 \%$ \\
\hline Oeste Paulista & $7.230(65,5 \%)$ & $69,7 \%$ & $3.807(34,5 \%)$ & $83,7 \%$ & $11.037(100 \%)$ & $73,9 \%$ \\
\hline
\end{tabular}

Fonte: Elaboração própria a partir das tabulações organizadas por Bassanezi (1998, p. 95; p. 361; p. 792).

Observação: PLT, PET e PT significam, respectivamente, população livre total, população escrava total e população total

Os dados da Tabela 6 permitem afirmar que a maior parte dos escravos mencionados no censo para ambas as regiões se encontravam dentro de nosso conceito amplo de PIA. Cerca de $16 \%$ da população escrava era composta por crianças. No caso dos livres, a população com $11 \mathrm{ou}$ menos anos formava cerca de $30 \%$ da população. Essa diferença pode ser explicada por carac- 
terísticas demográficas que costumam marcar sociedades escravistas. De um lado, os escravos apresentavam taxa de crescimento vegetativo menores que a da população livre. De outro, o predomínio de escravos em idade ativa, sobretudo jovens, comercializados no tráfico interno, inflava essa parcela da população.

Antes de avançar a análise pela estrutura da força de trabalho, é preciso realizar alguns apontamentos acerca da fonte utilizada. O censo traz o conceito de profissão. Ele é bastante amplo, pois mistura trabalho por atividades econômicas com ocupação. Também agrupa pessoas inseridas em diferentes inserções na base produtiva. No caso da agricultura, por exemplo, trabaIhadores dependentes, proprietários de plantations e posseiros são todos arrolados na categoria "lavoura". Outra manifestação da amplitude desse conceito é o fato de não separar as pessoas que trabalham em ambiente doméstico daquelas que exercem sua atividade produtiva em fazendas ou estabelecimentos manufatureiros.

Também é impossível separar as pessoas ativas das inativas, do ponto de vista produtivo. Nada nos autoriza a afirmar que a quantidade de indivíduos encaixados em cada ramo profissional corresponda, de fato, ao número de trabalhadores ativos naquele segmento. Afinal de contas, ter uma profissão pode significar a mera dotação de habilidades para atuação em uma determinada atividade. Não significa seu exercício pleno. Para que a pesquisa evoluísse, foi necessário conferir atividade a um conceito que não traz implicitamente essa característica.

O censo permite que se verifique como a população total era distribuída ao longo das mais variadas profissões apresentadas. Trata-se da principal amostra sobre a distribuição da população pelas atividades econômicas para o Brasil oitocentista, que nos permitiu remontar a uma estrutura da força de trabalho para as áreas estudadas.

Optamos por organizar todas as profissões mencionadas no recenseamento em 10 categorias. São elas: religiosos; profissionais liberais (inclui funcionários públicos); militares; manufatura e artesanato; comércio; agricultura (que engloba pesca e pecuária); serviços domésticos; criados e jornaleiros; capitalistas e proprietários; e, por fim, sem profissão. Dessa.forma, poderemos visualizar os elementos mais notáveis desta seção das tabulações do censo organizadas por Bassanezi (1998): a presença de muitas pessoas divididas entre a lavoura, a manufatura (urbana e rural) e os serviços domésticos. Também chama atenção a dimịnuta participação dos profissionais liberais e dos comerciantes na composição geral da população.

Centremos nossa análise sobre as parcelas mais ricas do agro paulista. Apresentamos, primeiramente, os dados representativos da manifestação da força de trabalho na região cafeeira mais ántiga da província: o Vale do Paraíba. 
Tabela 7 - População por profissões - Vale do Paraíba.

\begin{tabular}{|l|c|c|c|c|c|c|c|c|}
\hline \multirow{2}{*}{ Profissão } & \multicolumn{2}{|c|}{ Livres } & \multicolumn{3}{c|}{ Escravos } & \multicolumn{3}{c|}{ Total } \\
\cline { 2 - 8 } & NA & $\%$ PLIA(a) & $\%$ PIA & NA & $\%$ PEIA(b) & $\%$ PIA & NA & \%PIA(c) \\
\hline Religiosos & 5 & $0,08 \%$ & $0,05 \%$ & 0 & $0 \%$ & $0 \%$ & $0,05 \%$ \\
\hline Profissionais Liberais & 50 & $0,8 \%$ & $0,5 \%$ & 0 & $0 \%$ & $0 \%$ & 50 & $0,5 \%$ \\
\hline Militares & 17 & $0,2 \%$ & $0,19 \%$ & 0 & $0 \%$ & $0 \%$ & 17 & $0,19 \%$ \\
\hline Manufatura/Artesanato & 606 & $10 \%$ & $6,9 \%$ & 141 & $5,1 \%$ & $1,6 \%$ & 747 & $8,5 \%$ \\
\hline Comércio & 160 & $2,6 \%$ & $1,8 \%$ & 0 & $0 \%$ & $0 \%$ & 160 & $1,8 \%$ \\
\hline Agricultura & 3.580 & $59 \%$ & $40,6 \%$ & 2.320 & $85 \%$ & $26,3 \%$ & 5.900 & $67 \%$ \\
\hline Serviços Domésticos & 1.112 & $18,3 \%$ & $12,6 \%$ & 331 & $12,1 \%$ & $3,7 \%$ & 1.443 & $16,4 \%$ \\
\hline Criados e Jornaleiros & 409 & $6,7 \%$ & $4,6 \%$ & 160 & $5,8 \%$ & $1,8 \%$ & 569 & $6,5 \%$ \\
\hline Capitalistas e Proprietários & 33 & $0,5 \%$ & $0,3 \%$ & 0 & $0 \%$ & $0 \%$ & 33 & $0,3 \%$ \\
\hline Sem Profissão & 2.318 & $38 \%$ & $26,3 \%$ & 305 & $11 \%$ & $3,4 \%$ & 2.623 & $29,8 \%$ \\
\hline Total & 8.290 & & & 3.257 & & & $\mathbf{1 1 . 5 4 7}$ & \\
\hline
\end{tabular}

Fonte: Elaboração própria a partir das tabulações organizadas por Bassanezi (1998, p. 146-154; p. 619-627; p. 852-860).

*NA é o número absoluto, tal qual aparece no censo.

$a=$ população livre em idade ativa. $b=$ população escrava em idade ativa. $c=$ população em idade ativa.

Os dados em tela captam a realidade global do agro, e não apenas a lavoura escravista produtora de café - essa representava a camada superior da produção agrícola. Por apresentar maior lucratividade e produtividade, detinha maior potencial em mobilizar mão de obra cativa. As inferiores, identificadas com reduzidos estoques de riqueza, eram muito mais heterogêneas e mais identificadas pelas vendas no mercado interno, pelo limitado uso de escravos e pela maior mobilização relativa de trabalhadores livres.

De acordo com os dados da Tabela 7, mais de dois terços da população valeparaibana em idade ativa estava inserida na faina agrícola. É notável o alto aproveitamento dos escravos nessa atividade, uma vez que em seu entorno ocorria a exploração de $85 \%$ da população escrava em idade ativa. Não é exagero supor que a maioria desses cativos estivesse inserida na produção cafeeira. Aqueles inseridos nos mega-plantéis vivenciavam a experiência do trabalho nas plantations. De maneira geral, é correto afirmar que havia especialização da utilização do braço cativo na atividade principal.

Essa amostra apresenta uma utilização intensiva do potencial de força de trabalho materializado nos cativos, já que apenas $11 \%$ dos escravos maiores de 11 anos foram relacionados, no censo, na categoria "sem profissão". É bem possível que estes fossem divididos entre idosos, inválidos ou, até mesmo, escravos de ganho.

Também chama atenção o predomínio dos trabalhadores livres sobre os escravos na principal 
atividade econômica do Vale. Os escravos da lavoura representavam pouco mais de $25 \%$ do total da população em idade ativa, enquanto a participação das pessoas livres atingia mais de $40 \%$. Em termos absolutos, pouco mais de $60 \%$ da população inserida na agricultura era formada por livres. Cabe lembrar que o Vale estava entre as regiões econômicas do Império mais identificadas' com a plantation. A elevada participação dos livres na força de trabalho potencial mostra a relevância que eles tinham na economia rural em tela. Entendemos que a plantation esteve imersa em um panorama rural mais amplo, organizado em torno do trabalho livre.

Os braços livres da lavoura, parcela majoritária da força de trabalho, deviam estar disseminados no agro entre a cafeicultura, a produção de derivados de cana e, principalmente, a produção dos

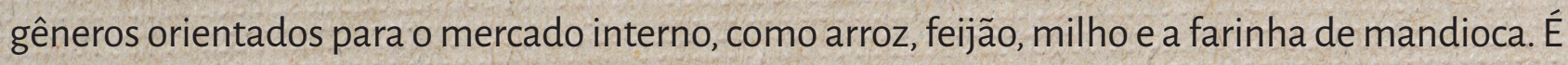
possível que a própria concentração de cativos na camada superior da produção agrícola tenha representado a abertura de espaços ainda mais amplos para a utilização econômica da população livre na agricultura, principalmente nos estratos subalternos do agro. O fato de ter havido um fluxo comercial intrarregional de braços cativos do patrimônio de pequenos produtores para o dos grandes potentados corrobora esse argumento.

Como mencionamos, o grupo dos profissionais da lavoura, captados no censo, engloba uma vasta gama de agentes sociais, desde proprietários de grandes fazendas a posseiros. O censo não permite qualquer tipo de desagregação. Com o intuito de separar a camada dos proprietários da massa de pessoas que compunha a mão de obra explorada no campo, utilizamos o já citado Almanak da Província de São Paulo (LUNÉ \& FONSECA, 1985).

Essa publicação arrola os nomes dos maiores fazendeiros de cada' comarca. Separamos o número de fazendeiros produtores de café, cana e algodão para cada uma das cidades que formam as amostras. A média para as cidades do Vale era de 84 fazendeiros, 1,4\% do total de pessoas vinculadas à lavoura pelos agentes recenseadores (LUNÉ \& FONSECA, 1985, p. 149-253). Essa evidência permite afirmar que as elites posicionadas nessas localidades eram minúsculas do ponto de vista demográfico. Esta forma de circunscrever os limites da elite rural é mais verossímil do que centrar apenas na categoria "capitalistas e proprietários", presente do censo, devido à maior amplitude abrangida.

A dimensão do artesanato na vida material do Vale devia ser bastante limitada. Essa atividade era desempenhada em oficinas situadas nos núcleos urbanos e, sobretudo, nos próprios domicílios. Porém, ela não era irrelevante do ponto de vista do engajamento de mão de obra, uma vez que mobilizava $8,5 \%$ da PIA. Essa não representa uma taxa desprezível de mobilização de mão de obra, tendo em vista a marcante especialização agrícola dessa economia. Quatro quintos das pessoas vinculadas a essa atividade eram livres. Um décimo dos livres em idade ativa estavam vinculados a essa atividade, enquanto $5 \%$ da população escrava em idade ativa se dedicava a ela. 
Menos relevante era a parcela da força de trabalho potencialmente assalariada, representada pela categoria "criados e jornaleiros". Cobriam 6,5\% da PIA. Por um lado, trabalhadores rurais pouco qualificados que tinham engate eventual na lavoura, como os camaradas, estavam inseridos nessa categoria. Por outro lado, trabalhadores qualificados também constavam nela, como pedreiros, carpinteiros ou técnicos da manufatura dos derivados de cana. Em termos absolutos, a presença de jornaleiros livres era mais de três vezes superior à dos escravos. Dentre esses, uma parcela poderia ser composta por escravos de ganho.

Chama atenção a imensa participação de pessoas livres em idade ativa terem sido arroladas pelos agentes recenseadores na categoria "sem profissão". Compunham mais de um quarto da PIA. Nossa interpretação para essa constatação segue a análise de Lamounier (2012, p. 244), para quem parcela substantiva desses indivíduos supostamente sem profissão pode ser encarada como trabalhadores temporários. Tratar-se-ia de uma parcela fluída da força de trabalho, que garantia seu sustento através da realização de tarefas ou empreitadas que exigiam pouca qualificação.

Se esse pressuposto de Lamounier estiver correto, podemos aproximar o pessoal "sem profissão" dos jornaleiros. Dessa forma, ampliamos para mais de um terço da PIA os contornos demográficos da parcela fluída da mão de obra, estratégica em uma economia caracterizada por oscilações de demanda por trabalho, determinadas pelo próprio ciclo da agricultura.

Tabela 8 - População por profissões- Oeste Paulista

\begin{tabular}{|c|c|c|c|c|c|c|c|c|}
\hline \multirow{2}{*}{ Profissão } & \multicolumn{2}{|c|}{ Livres } & \multicolumn{3}{|c|}{ Escravos } & \multicolumn{3}{|c|}{ Total } \\
\hline & $N A^{*}$ & \%PLIA(a) & \%PIA & NA & $\%$ PEIA(b) & $\%$ PIA & NA & \%PIA(c) \\
\hline Religiosos & 4 & $0,05 \%$ & $0,03 \%$ & 0 & $0 \%$ & $0 \%$ & 4 & $0,03 \%$ \\
\hline Profissionais Liberais & 74 & $1 \%$ & $0,6 \%$ & 0 & $0 \%$ & $0 \%$ & 74 & $0,6 \%$ \\
\hline Militares & 15 & $0,2 \%$ & $0,1 \%$ & 0 & $0 \%$ & $0 \%$ & 15 & $0,1 \%$ \\
\hline Manufatura/Artesanato & 931 & $12,9 \%$ & $8,5 \%$ & 274 & $7,2 \%$ & $2,5 \%$ & 1.205 & $11 \%$ \\
\hline Comércio & 252 & $3,5 \%$ & $2,2 \%$ & 0 & $0 \%$ & $0 \%$ & 252 & $2,2 \%$ \\
\hline Agricultura & 2.892 & $40 \%$ & $26,2 \%$ & 2.715 & $71,3 \%$ & $24,6 \%$ & 5.607 & $51 \%$ \\
\hline Serviços Domésticos & 1.289 & $17,8 \%$ & $11,6 \%$ & 552 & $14,5 \%$ & $5 \%$ & 1.841 & $16,7 \%$ \\
\hline Criados e Jornaleiros & 549 & $7,6 \%$ & $5 \%$ & 243 & $6,4 \%$ & $2,2 \%$ & 792 & $7,2 \%$ \\
\hline Capitalistas e Proprietários & 24 & $0,3 \%$ & $0,2 \%$ & 0 & $0 \%$ & $0 \%$ & 24 & $0,2 \%$ \\
\hline Sem Profissão & 4.339 & $60 \%$ & $39,3 \%$ & 761 & $19,9 \%$ & $6,9 \%$ & 5.100 & $46 \%$ \\
\hline Total & 10.369 & & & 4.545 & & & 14.914 & \\
\hline
\end{tabular}

Fonte: Bassanezi (1998, p. 146-154; p. 619-627; p. 852-860).

"NA é o número absoluto, tal qual aparece no censo.

$a=$ população livre em idade ativa. $b=$ população escrava em idade ativa. $c=$ população em idade ativa. 
Os serviços domésticos eram a atividade que mais mobilizava trabalhadores, depois da agricultura. A amostra colhida indica que $16 \%$ da PIA realizavam as tarefas típicas dos lares valeparaibanos. Do total absoluto, cerca de $23 \%$ eram indivíduos escravizados. Eles formavam $12 \%$ da população escrava em idade ativa. Os percentuais das mesmas categorias para o Oeste Paulista são semelhantes. Esses serviçais deviam estar vinculados aos fogos mais abastados da região. A tendência de alta do preço da mercadoria humana deve ter estimulado a redução do estoque de cativos nesta atividade improdutiva.

Verifiquemos a estrutura da força de trabalho posicionada no Oeste Paulista em comparação com a do Vale. Lembremos que o Oeste compunha, na época, a base a partir da qual erá promovida rápida expansão da fronteira agrícola, que se estendia pelo interior da Província. A disseminação da malha ferroviária, que atingia a marca de $306 \mathrm{~km}$ na região (CAMARCO, 1981, p. 174), facilitava este processo.

Tal qual no Vale, a agricultura era a atividade mais importante do ponto de vista da mobilização da força de trabalho: mais de $50 \%$ da PIA encontrava-se engajada no ofício. Enquanto $40 \%$ da população livre em idade ativa estava vinculada à lavoura, mais de $70 \%$ dos escravos na mesma faixa etária foram ligados à lavoura pelos agentes censitários.

É notável o fato de a faina agrícola apresentar, no Oeste, participação semelhante de livres e de escravos, em termos absolutos. Isso demonstra a capacidade apresentada pelos agentes econômicos de promover altas taxas de investimento nas décadas anteriores, apesar da dinâmica desfavorável do preço dos escravos. Indica um padrão de lucratividade elevado. O esforço realizado no âmbito do investimento e a incorporação de novas terras à agricultura de exportação foram estratégicos para que a região, poucas décadas à frente, viesse a ser a principal produtora mundial de café.

Também buscamos localizar no Almanak a dimensão demográfica da elite rural do Oeste Paulista através da listagem dos grandes fazendeiros de cada município. Realizamos o mesmo procedimento descrito linhas atrás para o caso do Vale. Chegamos à conclusão de que essa elite fazendeira compunha apenas $1,7 \%$ das pessoas ligadas à lavoura de acordo com os agentes censitários (LUNÉ \& FONSECA, 1985, p. 246-509). Portanto, a elite do Oeste era tão pequena quanto a do Vale.

Diferentemente do caso valeparaibano, as localidades que formam nossa amostra para o Oeste Paulista não eram sociedades escravistas maduras. As localidades recém-incorporadas à agricultura comercial eram povoadas por trabalhadores livres: os camaradas, utilizados na forma- 
ção e disseminação dos cafezais; os jornaleiros e empreiteiros, responsáveis pela construção ferroviária; os estrangeiros, que chegaram à região nas primeiras experiências imigrantistas; os agricultores não escravistas, que davam sentido ao seu uso da terra através da subsistência e da produção para mercados locais; além de um heterogêneo grupo de agricultores escravistas, dentre os quais uma pequena elite que dominava os grandes plantéis de escravos. De maneira geral, trata-se de uma estrutura social em constante transformação, organizada em torno dos grupos sociais promotores da expansão da fronteira agrícola.

Remontar esse contexto social é imperativo para a compreensão da grande dimensão da população livre com potencial participação na força de trabalho inserida pelos agentes censitários na categoria "sem profissão". Assumindo que, exceto idosos, parte substancial das pessoas arroladas nessa categoria fosse trabalhadores temporários não qualificados que vivenciavam experiências sociais semelhantes à dos jornaleiros, podemos afirmar que quase metade da população em idade ativa formava uma mão de obra volante capaz de se inserir nos mais diversos estratos do agro ou na construção das ferrovias, assim como na agricultura, no levantamento dos cafezais e na própria colheita de café como mão de obra subsidiária nos momentos de alta demanda por trabalho. No caso dos escravos, poderiam ser cativos de ganho ou disponíveis para o aluguel.

Essa forma de enxergar essa parcela da população é verossímil tendo em vista o fato das posições sociais e ocupacionais na região de fronteira agrícola não estarem tão bem definidas como nas sociedades rurais já amadurecidas. Parceiros, posseiros, camaradas, empreiteiros eram componentes de uma sociedade cuja estrutura social e força de trabalho eram caracterizadas, em essência, pela fluidez.

No que diz respeito ao engajamento da força de trabalho no artesanato, podemos afirmar que, no Oeste, essa atividade apresentava ainda maior capacidade em mobilizar trabalhadores. Dedicavam-se à manufatura $11 \%$ da PIA da região. O predomínio de livres nesse ramo da produção era notável. Tendo em vista que a cafeicultura era uma atividade intensiva em trabalho e que ela representava o motor da expansão da renda, consideramos que o artesanato apresentava, relativamente, alta capacidade em mobilizar trabalhadores.

Devemos lembrar que ambas as regiões, no começo da década de 1870 , estavam envolvidas na produção de algodão, cujo cultivo estava intimamente ligado à sua manufatura. O principal produtor desse gênero, dentre as cidades da amostra, era Sorocaba, que elevou a média da amostra do Oeste paulista. 
As amostras apresentaram uma força de trabalho cindida entre escravos e livres. No Vale, os últimos predominavam, enquanto no Oeste a força de trabalho era mais bem dividida entre ambos. Também notamos, para ambas as regiões, que parte relevante da população tinha vínculos intermitentes com a base produțiva. Diante dessas constatações, o seguinte questionamento vem à tona: a lavoura cafeeira estava assentada sob uma força de trabalho dual? Esse questionamento tem a concentração de cativos nessa lavoura como pressuposto real. Cabe especular se escravos e livres dividiam o mesmo espaço de trabalho na camada superior do agro.

Foge aos objetivos deste artigo propor uma explicação definitiva para esta questão. Porém, é possível lançar uma hipótese explicativa. Sua apresentação requer que dois elementos novos sejam somados à análise. Em primeiro lugar, a compreensão de padrões de relações sociais de produção que uniam livres pobres aos grandes fazendeiros. Em segundo, a articulação entre a dinâmica do preço do café no mercado internacional e a do câmbio.

É conhecido o fato de o mercado de trabalho rural ter sido caracterizado pela instabilidade e irregularidade da oferta e da demanda por trabalho. Como mencionamos, a oferta de escravos já não era mais abundante como fora nas décadas anteriores. A própria trajetória ascendente do preço dos cativos sinalizava esse fenômeno. Para além do braço escravizado, a força de trabalho também era composta por camaradas e parceiros.

Nossa reflexão recai sobre essas duas últimas figuras sociais. Os camaradas formavam uma reserva de mão de obra mobilizada durante a elevação da demanda por trabalho. Tessari (2012, p. 119) demonstrou a forte presença desse trabalhador volante no Oeste Paulista na passagem do século XIX para o XX. Além disso, como mencionamos, a atuação desses era estratégica para a disseminação dos cafezais na região de fronteira.

A parceria, por sua vez, era uma relação de dependência comum nas regiões agrícolas do Império. Prova disso é o fato da primeira experiência imigrantista para Rio Claro e Limeira, promovida por uma elite de fazendeiros, ter reproduzido essa forma de relação social de produção. Nela, o parceiro é inserido na terra do grande proprietário, cabendo a ele cuidar de determinado número de pés de café da fazenda. Isso envolvia limpeza dos cafeeiros, além da colheita, beneficiamento e secagem dos grãos. Além disso, os parceiros desfrutavam do direito costumeiro de levantar roças para o cultivo de alimentos nas fazendas. Tanto o café produzido quanto o excedente de alimentos eram comercializados, e o rendimento de ambos era dividido entre parceiro e proprietário (DEAN, 1977, p. 97).

Esse sistema era bastante confortável para o fazendeiro, já que era uma forma barata de mobilizar mão de obra em torno da lavoura. Além disso, era marcado pelo compartilhamento dos 
riscos inerentes a atividades entre o fazendeiro e seu parceiro. Os principais riscos que recaíam sobre a renda desses agentes econômicos eram as oscilações do câmbio e do preço do café.

O preço do café apresentou crescimento vigoroso no mercado norte-americano durante a segunda metade do século XIX. O ano de 1870 marcou o início de uma vigorosa disparada dos preços da rubiácea, encerrada sete anos depois. Neste curto intervalo, que cobre o momento da realização da pesquisa censitária, o preço do café aumentou $71 \%$. Esse crescimento pode ser explicado tanto pela redução das produções cafeeiras de Java e da América Central, quanto pelo dinamismo até então apresentado pela demanda externa.

Segundo Delfim Netto (2009, p. 24-25), a emissão de moeda por parte do governo durante a Guerra do Paraguai foi responsável pela elevação dos preços internos e pela desvalorização do câmbio. Assim, o câmbio favorável aos exportadores, as ascensões do preço e do volume exportado apontam para a vigência um padrão de lucratividade formidável entre 1850 e o final da década de 1870 , sobretudo em moeda nacional. Isso demostra que, durante todo o terceiro quartel do século XIX, formava-se uma conjuntura favorável tanto ao investimento quanto ao engajamento de parceiros na cafeicultura.

Em síntese, a mesma conjuntura econômica mesclava aumento da demanda por trabalho; elevação do preço dos escravos, sobretudo no Oeste Paulista; ascensão do preço da rubiácea no mercado internacional; e desvalorização cambial: Portanto, tratava-se de uma conjuntura dentro da qual a disseminação da relação de parceria era estratégica para a expansão da oferta paulista de café, uma vez que as condições do mercado favoreciam a expansão da renda de fazendeiros e de seus parceiros. Nesse sentido, é possível inferir que a proporção entre escravos e livres na força de trabalho, e a presença de muitos trabalhadores livres de participação intermitente nesta, sejam indicativos de que trabalhadores livres exercessem funções produtivas semelhantes às dos escravizados na lavoura exportadora montada em São Paulo em meados do século XIX.

Demonstramos que a economia rural posicionada nas regiões mais dinâmicas do agro paulista apresentou, já no terceiro quartel do século XIX, grande capacidade de mobilizar mão de obra livre, além da escravizada. Levando em consideração as condições de mercado, é possível que escravos e livres tenham compartilhado o mesmo espaço produtivo na faina cafeeira. Nossa interpretação representa mais um capítulo da desconstrução da clássica interpretação de Celso Furtado (1980) acerca da ausência da mão de obra livre na expansão agrícola na segunda metade dos oitocentos. Na contramão deste, traçamos um panorama mais complexo e potencialmente flexível do mundo do trabalho rural, composto por agentes de diferentes condições responsáveis por formar um dos fundamentos da acumulação da riqueza na Província. 
A análise dos dados do Recenseamento de 1872 confirma a interpretação de Lamounier (2012, p. 215) acerca do fato dos trabalhadores livres representarem um potencial significativo de mão de obra a ser utilizada de maneira produtiva nos momentos de elevação da demanda por trabalho, sobretudo durante a expansão da fronteira agrícola.

A pesquisa de Costa (1992, p. 65$)$ sobre a economia rural durante as três primeiras décadas do século retrasado demonstrou o predomínio dos agricultores não escravistas durante 0 arranque da cafeicultura no quinhão paulista do Vale do Paraíba, em 1830. Eles formavam $70 \%$ do total de produtores arrolados na amostra organizada para essa região. Segundo o autor, os não proprietários de escravos também participavam da produção dos gêneros mais nobres. As evidências produzidas por nosso trabalho empírico indicam continuidade em relação ao panorama traçado por Costa. Não negamos a nova dimensão tomada pela plantation na Província e nem a preeminência dos grandes proprietários de escravos na forte expansão do produto experimentada em ambas regiões durante o terceiro quartel dos oitocentos. Porém, indicamos a relevância da participação das pessoas livres na força de trabalho durante essa expansão.

Do ponto de vista lógico, a realidade remontada pela pesquisa para o terceiro quartel do século XIX apresenta conexões importantes em relação à traçada por Tessari (2012, p. 96) para o Oeste Paulista durante a virada do século XIX para o XX. A Abolição desfez a natureza dual da força de trabalho. Entretanto, alongamos para toda a segunda metade do século XIX e ampliamos para o Vale do Paraíba o caráter combinatório do vasto arranjo de força de trabalho sobre o qual esteve baseada a acumulação cafeeira. Em um primeiro momento, a combinação entre escravos e livres marcou a estrutura desse complexo arranjo. Em um segundo; colonos italianos dividiam o espaço produtivo com os trabalhadores volantes nacionais.

Consideramos problemáticas as interpretações dicotômicas que separam analiticamente trabalho livre, de um lado, e trabalho escravo, de outro. Acreditámos que a efetivação do potencial produtivo da força de trabalho tenha aproximado escravos e livres naquelas formações sociais rurais. A própria transição para o trabalho livre deve ser matizada por essa convivência entre indivíduos de diferentes condições sociais. É correto afirmar que São Paulo passou por uma transição particular devido à maciça presença dos trabalhadores estrangeiros. Porém, essa passagem foi realizada através de uma ruptura menos intensa do que a prevista em estudos clássicos de história econômica, devido à forte presença do trabal hador nacional livre nos arranjos de força de trabalho sobre os quais esteve alicerçada a economia cafeeira paulista. Seguimos, então, a visão de Eisenberg $(1989$, p. 167) acerca da existência de um lento processo de transição para o trabalho livre no Brasil durante a segunda metade do século XIX. 


\section{Considerações finais}

O artigo remontou a estrutura da força de trabalho no Vale do Rio Paraíba e no Oeste Paulista. Nossa análise se desenvolveu no sentido de verificar como a força de trabalho, composta por escravos e livres, era dividida entre as atividades econômicas desenvolvidas nas regiões mais importantes de São Paulo.

A fonte utilizada nos obrigou a manter uma visão geral de nosso objeto de estudo. Ou seja, não houve foco na manifestação da força de trabalho apenas na lavoura exportadora. A vantagem dessa perspectiva é representada pela possibilidade de análise da totalidade da economia rural, que unia a plantation, a produção de alimentos para o mercado interno, o artesanato etc.

O trabalho escravo predominava na agricultura bananalense e campineira durante o terceiro quartel dos oitocentos. Entretanto, as evidências levantadas durante a pesquisa demonstraram que essas cidades eram exceções nas respectivas regiões em que estavam inseridas. Nessas, o trabalho livre predominava sobre o cativo. Isso não nega a essencialidade do escravismo no processo de acumulação do setor exportador, mas nos ajuda a compreender a importância dos trabalhadores livres dentro desses sistemas de grande lavoura, convivendo e trabalhando lado a lado com os cativos.

Famílias de trabalhadores livres e uma minoria dos escravos também se dedicavam à produção de alimentos que sustentavam uma sociedade que crescia e se tornava cada vez mais complexa do ponto de vista demográfico. Se vista a partir de sua totalidade, a produção social da riqueza nas parcelas mais dinâmicas do agro paulista esteve baseada na exploração de uma força de trabalho dual durante a segunda metade do século XIX.

Durante os meados dos oitocentos notamos que a mesma conjuntura socioeconômica era caracterizada tanto pela dificuldade na reprodução do capital-escravista, quanto pelo crescimento demográfico e pelos estímulos para a mobilização de mão de obra livre. A consequência real dessa conjuntura foi a maior mobilização de mão de obra livre. Parceiros, camaradas, ao lado dos escravos, formaram mão de obra estratégica para o abastecimento da população e para o desenvolvimento da agricultura exportadora.

A alta do preço do braço cativo favoreceu a concentração de escravos nas mãos dos proprietários mais ricos. É possível que esse processo, expresso no comércio, tenha estimulado o aumento da participação dos livres na força de trabalho rural. As evidências levantadas pela pesquisa indicam que a população livre manteve papel estrutural nos arranjos de força de trabalho nas duas regiões. Dessa forma, o principal argumento desse artigo corrobora a interpretação de 
Lamounier (2012) acerca da forte presença de trabalhadores nacionais livres na força de trabalho de São Paulo durante a segunda metade do século XIX. Consequentemente, negamos o panorama da força de trabalho traçado por Furtado $(1980$, p. 120), marcado pela exclusão do trabalhador nacional.

Consideramos importante o fato de essa pesquisa ter conferido contornos empíricos à força de trabalho empregada na manufatura/artesanato. Cerca de $10 \%$ da força de trabalho potencial das localidades do Vale e do Oeste estavam ligadas a esse setor. Trata-se de uma alta mobilização de trabalhadores; em termos relativos, tendo em vista a marcante especialização agrícola das regiões estudadas. É muito provável que o nível de mobilização de mão de obra não tenha sido exceção no Brasil oitocentista. A evidência em tela joga luz sobre a necessidade de aprofundamento do estudo sobre a manufatura rural no período anterior ao desenvolvimento do capital industrial no país.

\section{Referências}

BASSANEZI, Maria Silvia C. Beozzo. São Paulo do Passado: dados demográficos. Campinas: Nepo/Unicamp, 1998.

CAMARCO, José Francisco de. Crescimento da população no estado de São Paulo e seus aspectoseconômicos. São Paulo: Instituto de Pesquisas Econômicas, 1981.

COSTA, Iraci del Nero da. Arraia-miúda: um estudo sobre os não proprietários de escravos no Brasil. São Paulo: MGSP, 1992.

DEAN, Warren. Rio Claro: um sistema brasileiro de grande lavoura 1820-1920. Rio de Janeiro: Paz e Terra, 1977.

DELFIM NETTO, Antônio. O problema do caféno Brasil. São Paulo: Unesp, 2009.

EISENBERG, Peter Louis. Homens Esquecidos: escravos e trabalhadores livres no Brasil - séculos XVIII e XIX. Campinas: Unicamp, 1989.

FURTADO, Celso. Formação Econômica do Brasil. São Paulo: Editora Nacional, 1980.

GOLDSMITH, Raymond. Brasil-1850/1984: desenvolvimento financeiro sob um século de inflação. São Paulo: Harper \& How do Brasil; Bamerindus, 1986.

HOLLOWAY, Thomas. Imigrantes para o café: café e sociedade em São Paulo (1886-1934). Rio de Janeiro: Paz e Terra, 1984. 
LAMOUNIER, Mária Lúcia. Ferrovias e mercado de trabalho no Brasil do século XIX. São Paulo: Edusp, 2012.

LUNA, Francisco; KLEIN, Herbert S. Escravismo no Brasil. São Paulo: Edusp; Imprensa Oficial, 2010.

LUNÉ, Antônio José Batista de; FONSECA, Paulo Delfino da. Almanak da Província de São Paulo para 7873. São Paulo: Imprensa Oficial do Estado; Arquivo do Estado, 1985.

MATTOS, Hebe. Ao sul da história: lavradores pobres na crise do trabalho escravo. Rio de Janeiro: FGV, 2015.

MILLIET, Sérgio. Roteiro do café e outros ensaios. São Paulo: Hucitec, 1982.

MOTTA, José Flávio. Escravos daqui, dali e de mais além: o tráfico interno de cativos na expansão cafeeira paulista (Areias, Guaratinguetá, Constituição/Piracicaba e Casa Branca). São Paulo: Alameda, 2012.

MÜLLER, Daniel Pedro. Ensaio d'um quadro estatístico da Província de São Paulo. 3. ed. facsimilada. São Paulo: Governo do Estado de São Paulo, 1978.

PETRONE, Maria Thereza S. A lavoura canavieira em São Paulo: expansão e declínio (1765-1851). São Paulo: Difel, 1968.

PIRES, Júlio M.; COSTA, Iraci del Nero da. O capital escravista mercantil e a escravidão nas Américas. São Paulo: Educ; Fapesp, 2010.

SLENES, Robert W. The Brazilian internal slave trade 1850-1888: regional economies, slave experience, and the politics of a peculiar market. In: JOHNSON, Walter. The Chattel Principle: internal slave trades in Americas. New Haven; London: Yale University Press, 2004.

TESSARI, Cláudia Alessandra. Braços para a colheita: sazonalidade e permanência do trabalho temporário na agricultura paulista (1890-1915). São Paulo: Alameda, 2012.

TOMICH, Dale. Pelo prisma da escravidão. São Paulo: Edusp, 2010. 
